\title{
A IMPORTÂNCIA DO DESENVOLVIMENTO PSICOMOTOR NA EDUCAÇÃO ESCOLAR, JUNTO À EDUCAÇÃO FÍSICA: UMA REVISÃO LITERÁRIA
}

\author{
DESARROLLO DE PSICOMOTRICIDAD IMPORTANCIA DE LA EDUCACIÓN \\ ESCOLAR A LA EDUCACIÓN FÍSICA: UNA REVISIÓN LITERARIA
}

\author{
THE IMPORTANCE OF PSYCHOMOTOR DEVELOPMENT IN SCHOOL \\ EDUCATION, WITH PHYSICAL EDUCATION: A LITERARY REVIEW
}

\author{
Giuliano Roberto da SILVA ${ }^{1}$ \\ Alexandre Maia REIS ${ }^{2}$ \\ Juliana Bonaccorsi Campos de OLIVEIRA ${ }^{3}$ \\ Cassiano Merussi NEIVA ${ }^{4}$ \\ Daniel dos SANTOS ${ }^{5}$
}

RESUMO: A Psicomotricidade tem por função destacar a relação entre a motricidade, a mente e a afetividade. Uma criança cuja Psicomotricidade não esteja bem desenvolvida pode apresentar dificuldades na aprendizagem escolar, por exemplo, a criança que não tem seu lado dominante definido pode apresentar dificuldade na leitura, confusão em discernir "b" de "d", dificuldades de copiar do plano vertical para o horizontal, dentre outras. Por isso vemos a importância de se trabalhar a Psicomotricidade desde o início da alfabetização, e a forma mais indicada é a forma lúdica. Este estudo teve como objetivo comprovar a importância do desenvolvimento psicomotor na educação escolar com a ajuda do profissional de Educação Física. Após a Revisão Literária, conclui-se que como ciência em prol da educação, a Psicomotricidade tem como objetivo educar o movimento, ao mesmo tempo em que desenvolve a inteligência e a afetividade. Portanto, a educação psicomotora é indispensável a toda criança. Toda escola deve promover estímulos para desenvolver em seus alunos as habilidades de esquema corporal, lateralidade, estruturação espacial, orientação temporal, tônus, postura e equilíbrio, pré-escrita e a psicomotricidade fina.

\footnotetext{
${ }^{1}$ Professor da Universidade José do Rosário Vellano - UNIFENAS (Alfenas-MG), Professor do Centro Universitário do Sul de Minas - UNIS-MG (Varginha-MG). Professor Efetivo na Rede Estadual de Ensino atua na Escola Estadual Coronel Joaquim Ribeiro (Nepomuceno-MG). Em academias atua na Espaço Saúde (Nepomuceno-MG) e Gym Center (Lavras-MG). Email: giumusc@ gmail.com

2 Pós Graduação "Lato Sensu" em Treinamento Desportivo - Universidade Federal de Minas Gerais. Atualmente professor das disciplinas Corpo e Movimento, Educação Física Escolar e Ética e Prática Educativa - Centro Mineiro do Ensino Superior. Email: alexandrexambinho@gmail.com

${ }^{3}$ Graduada em Educação Física pela Universidade Presidente Antônio Carlos (UNIPAC) - Campo Belo MG - Brasil. Email: jubonaccorsi@yahoo.com.br

${ }^{4}$ Livre-docente. Docente e Tutor junto aos cursos de Graduação em Medicina (método tradicional e PBL), Nutrição, Educação Física, Fisioterapia, Biologia e Psicologia. Disciplinas: Fisiologia de Sistemas Humanos, Neurofisiologia e Controle Neuro-Endócrino, Bioquímica e Metabolismo, Nutrição Humana, Nutrição e Exercício, Fisiologia do Esforço, Epidemiologia e Saúde Humana, Crescimento e Desenvolvimento, Atletismo, Artes Marciais, Pesquisa Quantitativa, Clinica e Experimental em Saúde Humana. Graduado pela Universidade Estadual Paulista (UNESP -1990). Email: cassiano.neiva@unifenas.br

${ }^{5}$ Docente-pesquisador do Programa de Mestrado e Doutorado em Promoção de Saúde e do curso de Educação Física- Universidade de Franca. Email: daniel.santos@unifran.edu.br
} 
PALAVRAS-CHAVE: Psicomotricidade. Educação Escolar. Educação Física.

RESUMEN: La función psicomotora es poner de relieve la relación entre las habilidades motoras, la mente y la afectividad. Un niño cuya psicomotricidad no está bien desarrollado puede tener dificultades en el aprendizaje escolar, por ejemplo, el niño que no tenga su lado dominante definida puede tener dificultades en la lectura, la confusión en el discernimiento "b" a "d", las dificultades para copiar el plano vertical a la horizontal, entre otros. Así vemos la importancia de trabajar para Psicomotridade desde el comienzo de la alfabetización, y la forma más apropiada es la forma lúdica. Este estudio pretende demostrar la importancia del desarrollo psicomotor en la educación con la ayuda de profesionales de la educación física. Después de la revisión literaria, se concluye que a medida que la ciencia en favor de la educación, psicomotor, tiene como objetivo educar al movimiento, mientras que el desarrollo de la inteligencia y la afectividad. Por lo tanto, la educación psicomotriz es esencial para todos los niños. Todas las escuelas deben promover incentivos para desarrollar en sus estudiantes las habilidades del esquema corporal, lateralidad, estructura espacial, la orientación temporal, tono, postura y el equilibrio, pre-escritura y la motricidad fina.

PALAVRAS CLAVE: Psicomotor. Educación Escolar. Educación Física.

ABSTRACT: Psychomotricity has the function to emphasize the relation between the motricity, the mind and the affectivity. A child whose Psychomotricity is not well developed may present difficulties in school learning, for example, a child who does not have a definite dominant side may have difficulty in reading, confusion in discerning "b" from "d", difficulty in copying from the vertical plane To the horizontal, among others. That is why we see the importance of working Psychomotrity since the beginning of literacy, and the most indicated form is the playful form. This study aimed to prove the importance of psychomotor development in school education with the help of the Physical Education professional. After the Literary Review, it is concluded that as a science for education, Psychomotricity, aims to educate the movement, while at the same time developing intelligence and affectivity. Therefore, psychomotor education is indispensable to every child. Every school should promote stimuli to develop in its students the skills of body schema, laterality, spatial structuring, temporal orientation, tone, posture and balance, pre-writing and fine psychomotricity.

KEYWORDS: Psychomotricity. Schooling. Physical Education.

\section{Introdução}

Este estudo aborda a importância do desenvolvimento psicomotor na Educação Física escolar e tem por objetivo evidenciar a importância do trabalho do professor de Educação Física, para o desenvolvimento de pré-requisitos básicos, como: esquema corporal, lateralidade, coordenação motora e viso-motor, estruturação, dentre outros, 
para a aprendizagem, seja ela escolar, física ou social. Deste modo, contribui para um melhor atendimento educacional, a partir da Psicomotricidade e dos benefícios que ela oferece para a educação escolar.

Para Hurtado (1991), a Educação Física representa um conjunto de atividades físicas, metódicas e racionais que se integram ao processo de educação global, visando o pleno desenvolvimento do aparelho locomotor, bem como ao desempenho normal das grandes funções vitais de um indivíduo e ao seu melhor relacionamento social.

Embora o trabalho com a Psicomotricidade seja apontado por muitos estudiosos como de fundamental importância na área educacional, seus princípios teóricos ainda são pouco conhecidos pela população acadêmica. Desta forma, isto justifica o presente estudo, que busca fornecer aos educadores, em especial aos professores de Educação Física, informações úteis ao seu trabalho.

Esta pesquisa abordada o que é a Psicomotricidade, fornecendo um breve histórico da mesma, evidenciando sua eficiência enquanto ciência e técnica, esclarecendo os papéis da estimulação psicomotora, da educação psicomotora, da reeducação psicomotora e da terapia psicomotora, e também aborda conceitos psicomotores, tais como: Esquema Corporal, Imagem Corporal e Tônus, e apresenta sugestões de exercícios para desenvolver habilidades de esquema corporal, lateralidade, estruturação espacial, orientação temporal, dentre outras.

Desta forma, pode-se dizer que se trata de um trabalho enriquecedor para a área educacional, pois evidencia pontos fundamentais da Psicomotricidade e sua eficácia de forma objetiva e prática.

Logo, o objetivo deste estudo foi evidenciar a contribuição do trabalho psicomotor como importante suporte para o processo de aprendizagem na Educação Escolar, tendo como mediadora a disciplina de Educação Física e, desta forma, contribuir para a melhoria do atendimento educacional a partir da Psicomotricidade.

\section{Metodologia}

Neste artigo foi feito extenso estudo bibliográfico de autores como Alves (1998), Bueno (1997), Cabral (2000), Foucault (1998), Lapierre (1988), Marx (1987, 2001), dentre outros, acerca da importância da Psicomotricidade para o processo de ensino e aprendizagem na Educação Escolar, e dentre tantos tipos de pesquisas possíveis, a 
pesquisa qualitativa descritiva (bibliográfica) apresenta características apropriadas para o foco principal.

\section{Revisão de Literatura}

\section{Psicomotricidade: breve histórico}

De acordo com Alves (1998), junto à história do corpo nasce a história da Psicomotricidade, pois o corpo é a fonte (biológica) de todos os comportamentos do indivíduo com a mãe e o mundo. A partir daí acontece, então, um longo percurso marcado às vezes por cortes revolucionários e reformulações decisivas para com a realidade do ser social.

Segundo Alves (1998), o termo Psicomotricidade apareceu no início do século passado, com os trabalhos de Dupré. Foi ele que estabeleceu diferença radical entre a motricidade e seu aspecto negativo, a relaxação. Foi a partir dessa época que apareceram, de fato, os primeiros trabalhos que constituíram o ponto de partida de uma elaborada reflexão sobre o movimento corporal. Conforme estudos desse mesmo autor, a passagem do modo de produção feudal para o modo capitalista implicou em grandes mudanças sociais, que envolveram diferentes dimensões: cultural, política, educacional e econômica.

Para Marx e Engels (1987), indústria e o comércio, a produção das necessidades de vida, condicionam, por seu lado, a distribuição, a estrutura das diferentes classes sociais, para serem, por sua vez, condicionadas por estas em seu modo de funcionamento. E embora a educação se proponha a ser igualitária para todos, esta ainda é uma educação reducionista e simplificada para atender tão somente às necessidades do sistema de produção capitalista, deixando restrito o conhecimento do corpo, impedindo assim que se conceba o homem como um ser integral: corpo - psique - cognição.

Para Silva (2002), de acordo com uma perspectiva de totalidade, psicomotricidade "é uma área do conhecimento que tem por objeto o corpo e o desenvolvimento humano em suas relações sociais e de produção".

\section{Conhecendo o Sistema Psicomotor Humano}


Conforme Vayer e Toulouse (1982), o Sistema Psicomotor Humano (SPMH), baseia-se em estruturas simétricas do sistema nervoso, compreendendo o tronco cerebral, o cerebelo, o mesencéfalo e o diencéfalo, que constituí a integração e a organização psicomotora da tonicidade, da equilibração e parte da lateralização e também de estruturas assimétricas, compreendendo os dois hemisférios cerebrais, que asseguram a organização psicomotora da noção do corpo, da estruturação espaçotemporal e da praxia global e fina, exclusivas de espécie humana devido à sua complexidade organizativa e sistemática (Figura 01).

Figura 01: Esquema do Sistema Psicomotor Humano.

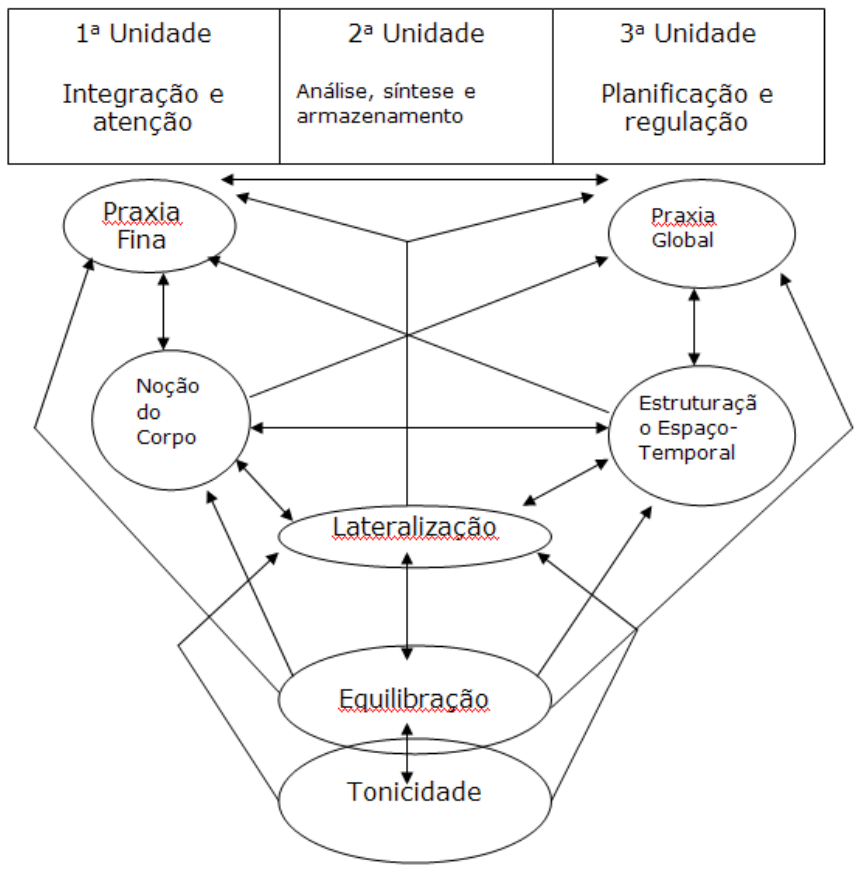

Fonte: (CUNHA, 1985).

Le Boulch (1983) esclarece que a educação psicomotora é formadora de uma base indispensável a toda criança, pois objetiva assegurar o desenvolvimento funcional. O SPMH é um todo único, composto de vários subsistemas ou fatores psicomotores, trata-se de um todo integrado. A noção de integração psicomotora é crucial ao SPMH. 


\section{Psicomotricidade, ciência e técnica}

Como foi visto no Congresso Brasileiro de Psicomotricidade e III Encontro de Profissionais de Psicomotricidade (1995), junto à Associação Brasileira de Psicomotricidade (1995), a Psicomotricidade é uma técnica advinda de múltiplos pontos de vista, utilizando as aquisições de várias ciências constituídas, como a biologia, a psicologia, a psicanálise, a sociologia e a linguística. É também considerada uma terapia, pois se dispõe a desenvolver as faculdades expressivas do indivíduo através da "linguagem corporal".

Na visão de Freire (1989), ao se perguntar o que é Psicomotricidade, uma série de noções aparecem, indo da concepção mais simples, como maturação do sistema nervoso, processos neuromotores, pré-requisitos, coordenação; aos aspectos relacionais da motricidade humana: corpo e emoção.

Estudiosos como Bueno (1997), Wallon (1995), Cabral (2000), Fonseca (1985) e Freire (1989), podem explicitar a abrangência da Psicomotricidade, levando-se em conta que: PSICO refere-se aos aspectos Biomaturacionais (maturação do sistema nervoso), Cognitivos (responsável pela aprendizagem) e Afetivos (está relacionado aos sentimentos).

Com base nestes conceitos inter-relacionados, a Sociedade Brasileira de Psicomotricidade (1995), em Congresso realizado com profissionais de Psicomotricidade, elaborou um conceito geral: "Uma ciência que tem por objeto o estudo do Homem, através de seu corpo em movimento, nas relações com seu mundo interno e externo". Neste encontro concluiu-se também que a intervenção no campo psicomotor é concebida a partir de quatro áreas, a saber: estimulação, educação, reeducação e terapia psicomotora.

\section{Estimulação psicomotora}

Bueno (1997), em seu livro Psicomotricidade: teoria e prática, faz a seguinte afirmativa sobre a estimulação psicomotora:

Entende-se por estimulação psicomotora o [processo] que envolve contribuições para o desenvolvimento harmonioso da criança no começo da vida. Caracteriza-se por atividades que se preocupam e vão 
ao encontro das condições que o indivíduo apresenta, acima de tudo, na sua capacidade maturacional, procurando despertar o corpo e a atividade por meio de movimentos e jogos e buscando a harmonia constante. Estimulação quer dizer despertar, desabrochar o movimento. Dirige-se prioritariamente a recém-natos e pré-escolares. Alguns autores referem-se à estimulação psicomotora como estimulação precoce, mas consideramos o termo errôneo, sendo mais sensato utilizarmos estimulação essencial (BUENO, 1997, p.83).

\section{Educação psicomotora}

Para Cabral (2000), educação psicomotora refere-se a todas as aprendizagens da criança, as quais se processam em etapas progressivas e específicas, em conformidade com o desenvolvimento de cada indivíduo. Tal desenvolvimento se dá em todos os momentos da vida através das percepções vivenciadas, como uma intervenção direta a nível cognitivo, motor e emocional, estruturando o indivíduo como um todo.

Segundo Le Boulch (1983), a educação acontece pela facilitação das condições naturais e da prevenção de distúrbios naturais dirigindo-se, prioritariamente, a crianças em condições de frequentar a escola e sem comprometimentos sérios. A educação realiza-se nos mais variados espaços, como: na escola, na família e no meio social, sendo mediada pelos educadores, pelos pais e professores em geral (magistério, natação, balé, judô, ginástica, dança, etc.).

Le Boulch (1983) lutou e conquistou, na década de 60, a inclusão da educação psicomotora nos cursos primários das escolas francesas. Para ele "a educação psicomotora deve ser considerada uma educação de base na escola elementar, ponto de partida de todas as aprendizagens pré-escolares e escolares”. A psicomotricidade tem por função destacar a relação entre a motricidade, a mente e a afetividade, e facilitar a abordagem global da criança, e a função motora, o desenvolvimento intelectual e o desenvolvimento afetivo estão intimamente ligados na criança.

Para Alves (1998), a maioria das crianças que passam por dificuldades na escolaridade, a causa do problema não está no nível cognitivo da classe a que chegaram, mas bem antes, está no nível das bases. Ou seja, os elementos básicos ou "prérequisitos", condições mínimas necessárias para uma boa aprendizagem, constituem a estrutura da educação psicomotora.

De acordo com Hurtado (1991), uma criança cujo esquema corporal é mal constituído não coordena bem os movimentos. Notadamente é atrasada quando se despe 
e as habilidades manuais lhe são difíceis. Na escola a caligrafia é feia, e a leitura inexpressiva, não-harmoniosa: o gesto vem após a palavra; a criança não segue o ritmo da leitura ou então para no meio de uma palavra.

Para Hurtado (1991), uma criança cuja lateralidade não está bem definida encontra problemas de ordem espacial, não percebe diferença entre seu lado dominante e o outro lado, não distingue a diferença entre esquerda e a direita e é incapaz de seguir a direção gráfica (leitura começando pela esquerda). Igualmente não consegue reconhecer a ordem em um quadro. É nesta hora que a atuação do professor de Educação Física deve fazer-se valer. Um trabalho eficiente de esquema corporal certamente amenizará profundamente tais déficits.

No olhar de Cabral (2000), diante de problemas de percepção espacial uma criança não é capaz de distinguir a letra "b" da letra "d", letra "p" da letra "q", número " 21 ” do número "12", caso não perceba a diferença entre esquerda e a direita. Se não distingue bem o alto e o baixo, confunde a letra " $b$ " da letra "p", letra " $n$ " da letra " $u$ ", o conectivo "ou" do "on".

Ainda na ótica de Cabral (2000), os problemas quanto à orientação temporal e a orientação espacial, como, por exemplo, com a noção "antes-depois", acarretam principalmente confusão na ordenação dos elementos de uma sílaba. A criança sente dificuldade em reconstruir uma frase cujas palavras estejam misturadas, sendo a análise gramatical um quebra-cabeça para ela. Da mesma forma, uma má organização espacial ou temporal acarreta fracasso na matemática. Com efeito, para calcular, a criança deve ter pontos de referência, colocar os números corretamente, possuir noção de "fileira", de "coluna"; deve conseguir combinar as formas para fazer construções geométricas.

Embasado em tais fatos, Lapierre (1988), afirma que a educação psicomotora "é uma ação psicopedagógica que utiliza os meios da educação física, com a finalidade de normalizar ou melhorar o comportamento do indivíduo".

Reforçando o pensamento de Le Boulch (1983), Vayer (1982) destaca que do ponto de vista educativo, o papel e lugar da educação psicomotora na educação geral corresponderá, naturalmente, às diferentes etapas do desenvolvimento da criança, e assim entendemos que: no curso da primeira infância, toda educação é educação psicomotora; no curso da segunda infância, a educação psicomotora permanece sendo o núcleo fundamental de uma educação educativa que começa a diferenciar-se em atividades de expressão, organização das relações lógicas e as necessárias aprendizagens de leitura-escrita-ditado; no curso da 'grande infância', a diferenciação 
entre as atividades educativas se faz mais acentuadamente, e a educação psicomotora mantém então a relação entre as diversas atividades que concorrem simultaneamente ao desenvolvimento de todos os aspectos da personalidade.

\section{Reeducação psicomotora}

Segundo De Meur e Staes (1984), reeducação psicomotora é entendida como uma ação que é desenvolvida em indivíduos que sofrem com perturbações ou distúrbios psicomotores, e tem por objetivo retomar as vivências anteriores e/ ou fases de educação ultrapassadas inadequadamente; ou seja, educar o que o indivíduo não assimilou adequadamente em etapas anteriores.

Para Bueno (1997), a tarefa da reeducação psicomotora é fazer com que o indivíduo possa adaptar-se ao seu meio, seja escolar, familiar ou social, sem que para isso tenha que renunciar à sua personalidade, mas, ao contrário, sabendo conhecer e dominar o seu corpo, através do qual todas as trocas são possíveis. Assim posto, a reeducação é aplicada por várias áreas profissionais: pedagogia, educação física, fonoaudiologia, fisioterapia, terapia educacional, psicologia e por arte-educadores, educadores, médicos da especialidade motora ou psíquica, entre outros.

Ainda de acordo com Bueno (1997), condição básica para uma boa reeducação está na tranquilidade e no intercâmbio afetivo entre o reeducador e o reeducando. Embasa sua eficácia no fato de que se remonta às origens, aos mecanismos de base que estão na origem da vida mental, controle gestual e do pensamento, controle das reações tônico-emocionais, equilíbrio, fixação na atenção, justa preensão do tempo e do espaço.

\section{Terapia psicomotora}

A terapia psicomotora é dirigida a indivíduos com conflitos mais profundos na sua estruturação, associados aos (aspectos) funcionais ou com desorganização total de sua harmonia corporal e pessoal. Envolve, por exemplo, crianças com agressividade acentuada, pulsões motoras incontroladas, casos de excepcionalidade e dificuldades de relacionamento corporal, e também destinada a indivíduos que possuem associação de 
transtornos da personalidade. Está baseada nas relações e na análise dessas relações por meio do jogo de movimentos corporais (BUENO, 1997).

Para este autor, a terapia psicomotora é fator prioritário para as questões biológicas, cognitivas e de comportamento, onde é mais amplamente adotada.

Segundo Silva (2002), o estudo da Psicomotricidade é recente. Ainda no início deste século o assunto era abordado apenas excepcionalmente. Atualmente, devido à grande demanda por parte das crianças, o estudo ultrapassa os problemas motores, pesquisando também as ligações com a lateralidade, a estruturação espacial e a orientação temporal por um lado e, por outro, as dificuldades escolares de crianças de inteligência normal. Faz também que se tome consciência das relações existentes entre o gesto e a afetividade.

Segundo Cabral (2000), ao observar uma criança de 2 anos que brinca com um jogo de ovos que se encaixam nota-se que ela segura o ovo e sente-o com as mãos; com a boca percebe que esse objeto é duro, liso e de forma arredondada. A criança o olha e sua visão confirma as suas impressões táteis: não existem pontas nem arestas; o objeto não muda de forma quando é tocado; é colorido. A criança joga-o no chão, ouve o barulho da queda do objeto, o vê rolar. Com base nestas observações pode-se concluir que: a partir de uma experiência simples de origem motora a criança vai recebendo inúmeras informações que serão classificadas paulatinamente em um conjunto de indicações similares percebidas em outras circunstâncias.

De acordo com Fonseca (1996), pode-se concluir então que a função motora, o desenvolvimento intelectual e o desenvolvimento afetivo estão intimamente ligados à criança. Portanto, a Psicomotricidade visa destacar a importância da motricidade, da mente e da afetividade no processo da aprendizagem.

Segundo Le Boulch (1983), pode-se reafirmar que a educação psicomotora é uma técnica, e para utilizá-la é necessário seguir algumas etapas que levem a criança a adquirir a noção de esquema corporal, assim como outras noções indispensáveis ao seu desenvolvimento. Cada noção é abordada primeiro através de exercícios motores. Ou seja, exercícios em que o corpo se desloca e o sujeito percebe as diferentes noções, de maneira interna. Depois, através de exercícios sensoriomotores em virtude dos quais a manipulação de objetos possibilita a percepção de diversas noções e, finalmente, através de exercícios perceptomotores, em que as manipulações são mais sutis e a percepção visual muito importante, domina as outras partes. Tais exercícios possibilitam uma 
análise profunda das funções intelectuais motoras, tais como a análise perceptiva, a precisão da representação mental, a determinação de pontos de referência.

Segundo Fonseca (1985), a Psicomotricidade abrange cinco etapas: i) a formação do "eu" da personalidade da criança, isto é, o desenvolvimento do esquema corporal através do qual a criança toma consciência de seu corpo e das possibilidades de expressar-se por meio desse corpo; ii) a criança percebe que seus membros não reagem da mesma forma: dominância lateral; iii) a maneira como a criança se localiza no espaço que a circunda e como situa as coisas, umas em relação às outras: trata-se da estruturação espacial; iv) a orientação temporal diz respeito à maneira como a criança se situa no tempo; v) como a criança se expressa também através do desenho, completa-se o estudo com o domínio progressivo do desenho e do grafismo.

\section{Psicomotricidade e conceitos psicomotores}

\section{Esquema Corporal}

De acordo com Hurtado (1991), o Esquema Corporal é o elemento básico, indispensável na criança para construção de sua personalidade. É a representação mais ou menos global, mais ou menos específica e diferenciada que ela apresenta de seu próprio corpo.

Vayer (1982), descreve a imagem corporal como resultado complexo de toda atividade cinética, sendo a imagem do corpo a síntese de todas as mensagens, de todos os estímulos e de todas as ações que permitam à criança se diferenciar do mundo exterior e de fazer do "eu" o sujeito de sua própria existência.

Já Ledoux (1991), descreve que o esquema corporal especifica o indivíduo como representante da espécie. Mais ou menos idêntico em todas as crianças da mesma idade, ele é uma realidade de fato, esteio e intérprete da imagem do corpo. Graças a ele, o corpo atual fica referido no espaço à experiência imediata. À medida que a criança conhece seu corpo e percebe que ele lhe obedece, vai tomando consciência de que pode utilizá-lo não só para movimentar-se, mas também para agir conforme seu desejo e controle, ela então vai sentir-se muito bem.

De acordo com Wallon (1989), a Psicomotricidade define o esquema corporal como a organização de estruturas cerebrais que concede ao indivíduo o conhecimento 
progressivo das partes e funções do corpo, a partir de etapas sucessivas, que são determinadas pela maturação neuro-cortical e pela relação da pessoa com o meio físico e humano. Desta forma, o esquema corporal propicia ao indivíduo noções de globalidade de si, equilíbrio postural, afirmação da lateralidade, entre outras habilidades.

Segundo Ledoux (1991), a criança ou aluno cujo esquema corporal não está bem elaborado em sua percepção, certamente apresentará dificuldade de coordenação dos seus movimentos. Irá atrapalhar-se ao se vestir ou despir, as habilidades manuais lhe serão difíceis e penosas. Na escola apresentará caligrafia feia e leitura não-expressiva, sem ritmo e entrecortada. Desta forma, exercícios de identificação, reconhecimento, localização e conhecimento das funções das partes do corpo auxiliam o desenvolvimento do esquema corporal.

\section{A imagem do corpo}

Comunicação sensorial (emocional) e a fala do outro aparecem como dois substratos dessa imagem do corpo. A simples experiência sensorial (corpo a corpo), sem um mediador humano, só instrui o esquema corporal e não estrutura a imagem do corpo. “[...] viver num esquema corporal, sem imagem do corpo, equivale ao 'viver mudo', solitário"(LEDOUX, 1991).

Segundo Galvão (1996), a estruturação da imagem do corpo, que é essencialmente relacional e inconsciente, apóia-se na dialética entre o próprio desejo e o desejo do outro, influenciando nos modos de relação que o indivíduo vai empreender com os outros, consigo mesmo e com as coisas.

O ser humano, portanto, constrói a visão do eu e da imagem dos seus corpos intimamente associados, ambos dependentes do desenvolvimento do sistema sensorial/neurológico, da percepção e de relações sociais/culturais.

Nesse sentido, Tavares (2003) descreve que nossa imagem corporal representa uma experiência muito especial, uma vez que o objeto em foco corresponde ao nosso eu. Inclui aspectos conscientes e inconscientes. Ela está vinculada à minha identidade e à minha experiência existencial. É tão espetacularmente dinâmica como são minhas relações com o mundo e como é a interação entre meus aspectos conscientes e inconscientes. 


\section{Habilidades Psicomotoras no Processo de Alfabetização}

Segundo Fonseca (1996), os jogos, regras e brincadeiras que estimulem a cognição, além de tudo, o que engloba os recursos motores para que a criança possa se ambientar nessa nova fase, a Educação Física pode e deve se orientar para atender as necessidades da alfabetização e minimizar os distanciamentos entre as crianças dotadas de diferentes habilidades. Em forma de aprendizagem lúdica é mais fácil para a criança aprender e erradicar sua deficiência e sua falha, possibilitando uma alfabetização mais tranquila para a criança, segura para a escola e satisfeita para os pais. No Ensino Fundamental, nas Séries Iniciais, as atividades que envolvem ritmo, criatividade, desenhos, bem como pintar, classificar e reconhecer, são desenvolvidos no hemisfério direito; já as aprendizagens primárias, desenvolvidas no hemisfério esquerdo, englobam a leitura, a escrita, a lógica, os números e a matemática.

De acordo com Wallon (1995), o movimento não é puramente um deslocamento no espaço, nem uma simples contração muscular, e sim, um significado de relação afetiva com o mundo, assim, para o autor, o movimento é a única expressão e o primeiro instrumento do psiquismo. Neste contexto, pode-se dizer que o desenvolvimento motor é precursor de todas as demais áreas.

De Meur e Staes (1984), assinalam que: o intelecto se constrói a partir da atividade física. As funções motoras (movimento) não podem ser separadas do desenvolvimento intelectual (memória, atenção, raciocínio) nem da afetividade (emoções e sentimentos). Para que o ato de ler e escrever se processe adequadamente, é indispensável o domínio de habilidades a ele relacionado, considerando que essas habilidades são fundamentais para as manifestações psicomotoras.

Segundo Hurtado (1991), a Educação Física representa um conjunto de atividades físicas, metódicas e racionais que se integram ao processo de educação global, visando o pleno desenvolvimento do aparelho locomotor, bem como ao desempenho normal das grandes funções vitais de um indivíduo e ao seu melhor relacionamento social.

Oliveira (1997), postula que é pela motricidade e pela visão que a criança descobre o mundo dos objetos, e é manipulando-os que ela redescobre o mundo, porém, esta descoberta a partir dos objetos só será verdadeiramente frutífera quando a criança for capaz de segurar e de largar, quando ela tiver adquirindo a noção de distância entre ela e o objeto que ela manipula. 
Molinari e Sens (2002), afirmam que a educação psicomotora nas séries iniciais do ensino fundamental atua como prevenção. Com ela podem ser evitados vários problemas, como a má concentração, confusão no reconhecimento de palavras, confusão com letras e sílabas e outras dificuldades relacionadas à alfabetização. Uma criança cujo esquema corporal é mal formado não coordena bem os movimentos. Suas habilidades manuais tornam-se limitadas, a leitura perde a harmonia, o gesto vem após a palavra e o ritmo de leitura não é mantido, ou então é paralisado no meio de uma palavra.

Fonseca (1996), destaca o caráter preventivo da Psicomotricidade, afirmando ser a exploração do corpo, em termos de seus potenciais, uma "propedêutica das aprendizagens escolares", especialmente a alfabetização. Para o autor, as atividades desenvolvidas na escola, como a escrita, a leitura, o ditado, a redação, a cópia, o cálculo, o grafismo, e enfim, os movimentos, estão ligados à evolução das possibilidades motoras, e as dificuldades escolares estão, portanto, diretamente relacionadas aos aspectos psicomotores.

Para Lagrange (1977), a criança ao nascer é um ser indiferenciado e difuso, não consciente de si e de seu corpo, à medida que começa a se locomover, engatinhar, subir, descer escadas, entrar em contato com os outros, passa a tomar consciência de seu corpo e suas partes nas interligações. A partir desse momento percebe que é um indivíduo independente da pessoa e cria um tipo de complicação vivida ao nível do corpo.

Para Fonseca (1985), a educação psicomotora, mediada pelas aulas de Educação Física, tem muito a contribuir, porque tem como promover atividades que aprimorem essas características citadas acima; trabalhando paralelamente essas ações, respeitando o progresso da constituição fisiológica da criança e auxiliando esse processo. O Educador Físico das séries iniciais do Ensino Fundamental deve, através de atividades que desenvolvam noção de tempo, espaço e ritmo, estimular as crianças de maneira prazerosa e desafiadora, enfatizando a verbalização, memória, raciocínio e principalmente conferindo sentido a esse processo.

\section{Atividades Psicomotoras}


Para De Meur e Staes (1984), as atividades psicomotoras podem ser consideradas como ações a serviço da educação, pois elas cuidam do movimento e, ao mesmo tempo põem em jogo as funções intelectivas e a afetividade.

Segundo os autores acima, geralmente, crianças com distúrbios psicomotores apresentam: i) deficiência na formação de conceitos; ii) falhas de percepção e de discriminação de orientação espaço-temporal, no esquema corporal, na discriminação figura-fundo isto é, na capacidade de integrar estímulos, formando um todo compreensível; iii) atraso nos níveis de desenvolvimento motor (sentar, engatinhar e andar); iv) falta de coordenação motora; v) dificuldade na leitura e na escrita; vi) problemas de fala e de linguagem, como: dislalias, ou atropelamento da fala e gagueira, dentre outras alterações; vii) lentidão na realização dos trabalhos escolares; viii) fácil fatigabilidade; ix) dificuldades em copiar do plano vertical (quadro-de-giz) para o plano horizontal (caderno); $\mathrm{x}$ ) disgrafias, disortografias e a escrita em espelho; xi) lateralidade indefinida, dentre outros sintomas.

\section{Desenvolvendo habilidades}

De acordo com Freire (1989), para desenvolver habilidades faz-se necessário trabalhar:

A) Esquema Corporal: i) aplicar conceitos espaciais (que envolvam a noção de onde) e temporais (envolvem a noção de quando), no próprio corpo, no dos outros, no de bonecos ou desenhos de pessoas; ii) perceber e reproduzir movimentos e ritmos, com partes do corpo; iii) manter o equilíbrio estático, reproduzindo e mantendo posições; iv) expressar com o corpo diversos sentimentos; v) realizar movimentos complexos e diferenciados; vi) dissociar movimentos, com vários segmentos corporais, dentre outros.

B) Lateralidade: refere-se ao estabelecimento da dominância lateral da mão, olho e pé, do mesmo lado do corpo. O desenvolvimento da lateralidade inclui exercícios que envolvam os membros inferiores, os membros superiores e os olhos, como: i) jogos que levem ao uso sistemático da mão e do pé; ii) brincar com massa plástica, recortar linhas, figuras geométricas e figuras em geral; iii) desenhar, colorir, pintar; iv) chutar, 
pular com o pé dominante; v) brincar com caleidoscópio; vi) mirar alvos através de orifícios, telescópio; etc.

C) Estruturação Espacial: a estruturação espacial permite à criança conscientizar-se da situação de seu corpo em determinado meio ambiente. Para o autor a criança com problemas de estruturação espacial não perceberá a diferença entre posições à esquerda ou à direita. Ex: letra "b" e letra “d", letra "p" e letra "q", letra "n" e letra "u", etc. Deve-se trabalhar com exercícios que desenvolvam: i) a posição e a relação no espaço de indivíduos, objetos e situações; ii) a compreensão das relações espaciais que envolvem noções de acima, abaixo, no meio, maior, menor, igual, fora, dentro, longe, perto; etc.

D) Orientação Temporal: as noções de tempo são bem abstratas, daí serem mais difíceis de serem adquiridas pelas crianças. As atividades sugeridas são: i) sucessão de acontecimentos (antes, após, durante); ii) duração de intervalos (de tempo longo, de tempo curto); iii) ritmo regular e ritmo irregular (aceleração, freada); iv) locomoção rápida e lenta (diferença entre correr e andar); v) renovação cíclica de certos períodos (os dias da semana, os meses, as estações); vi) o caráter irreversível do tempo (hoje tenho seis anos, ano que vem terei....); vii) fazer com que as crianças avaliem o tempo necessário para escrever seu nome, ir até a outra sala, apontar o lápis, chegar até a escola, etc., sem cobrança de rapidez ou críticas de demoras; viii) explicar linha de tempo, começando com o nascimento até o presente, bem como a projeção para o futuro; ix) criar linhas de tempo para os futuros dias, semanas, meses.

E) Tônus, Postura e Equilíbrio: de acordo com Tavares (2003), para o desenvolvimento do tônus, da postura e do equilíbrio são necessários, dentre outros, exercícios para o fortalecimento da tonicidade dos músculos posturais, equilíbrio estático, flexibilização da coluna vertebral, equilíbrio dinâmico e força muscular. São sugeridas atividades como: i) equilibrar-se num dos pés com algum objeto na cabeça; ii) movimentar-se batendo com os pés no chão, alternadamente; iii) andar nas pontas dos pés, nos calcanhares, nas bordas dos pés, fazendo alongamento ou carregando na cabeça objetos de formas e pesos diferentes; iv) flexionar o tronco na posição sentada; v) passar o peso do corpo para a perna esquerda, para a direita, sem mexer os pés, com os olhos fechados ou abertos. 
F) Pré-escrita, psicomotricidade fina: para Cunha (1985), geralmente, crianças que têm problemas na coordenação dinâmica manual, apresentam problemas visomotores, com dificuldades para desenhar, recortar, escrever. Os exercícios motores para a pré-escrita e leitura colaboram para a educação de ambas as mãos e todos os dedos, desenvolvendo movimentos simultâneos ou dissociados, estes, diferentes em cada membro do par. Sugerem-se atividades como: i) lançar e receber bolas, picar, rasgar e recortar papel, abrir e fechar as mãos; ii) para desenvolver o grafismo da préescrita, os exercícios compreendem basicamente o uso dos dedos para passar sobre traçados de linhas retas, curvas, dentadas, etc., feitas em cor no quadro-de-giz, no papel ou outros materiais; iii) tatear formas desenhadas e recobertas com barbante, sisal, areia ou arroz; iv) tatear os próprios objetos; v) fazer pinturas; vi) traçar linhas horizontais ou verticais; vii) realizar movimentos de pinça, como catar sementes, colar pequenos grãos sobre linhas; viii) usar lápis, pincéis e giz, nos planos horizontal e vertical; ix) executar movimentos ritmados, concomitantes ou dissociados, utilizando as mãos ou os dedos.

\section{Considerações Finais}

Como foi demonstrado ao longo deste estudo, a Psicomotricidade nasceu da necessidade de moldar o homem em instrumento fabril, exigido pela sociedade capitalista. Em razão disso a educação escolar também se adequou às necessidades das classes dominantes, tornando-se diferenciada para a classe fabril.

Para conceituar esta área do conhecimento e bem utilizar os benefícios que a mesma pode oferecer para a educação global do educando, torna-se necessário superar a visão tendencialmente positivista e biologista que ela vem sendo, historicamente, concebida, e apreender a Psicomotricidade enquanto prática social, ou seja, concebê-la numa perspectiva de totalidade.

Atualmente, a intervenção no campo psicomotor é concebida a partir de quatro áreas, a saber: estimulação, educação, reeducação e terapia psicomotora. Por esta razão, pode-se afirmar que a área mais afim para desenvolver este trabalho é a Educação Física. 
Desta forma, as atividades da Educação Física podem ser consideradas ações a serviço da educação, pois elas cuidam do movimento, e ao mesmo tempo põem em jogo as funções intelectivas e a afetividade.

Como ciência em prol da educação, a Psicomotricidade tem como objetivo educar o movimento, ao mesmo tempo em que desenvolve a inteligência e a afetividade. Portanto, a educação psicomotora é indispensável a toda criança.

Toda escola deve promover estímulos para desenvolver em seus alunos as habilidades de esquema corporal, lateralidade, estruturação espacial, orientação temporal, tônus, postura e equilíbrio, pré-escrita e a psicomotricidade fina.

\section{Referências}

ALVES, G. L. A produção da escola pública contemporânea. Dissertação (Mestrado em Educação), Unicamp, Campinas, SP, 1998.

BUENO, J. M. Psicomotricidade: teoria e prática. $1^{\text {a }}$ ed. São Paulo: Editora Lovise, 1997.

CABRAL, S. Psicomotricidade relacional: prática clínica e escolar. $2^{\mathrm{a}}$ ed. Rio de Janeiro: Editora Revinter, 2000.

CONGRESSO BRASILEIRO DE PSICOMOTRICIDADE E III ENCONTRO DE PROFISSIONAIS DE PSICOMOTRICIDADE. Associação Brasileira de Psicomotricidade, $3^{\mathrm{a}}$ ed. Rio de Janeiro, 1995.

CUNHA, N. H. S. Sistema de estímulo pré-escolar: psicomotricidade e materiais didáticos. $1^{\text {a }}$ ed. São Paulo: Editora Cortez, 1985.

DE MEUR, A.; STAES, L. Psicomotricidade: educação e reeducação. $1^{\text {a }}$ ed. Rio de Janeiro, Editora Manole, 1984.

FOCAULT, M. Vingar e punir: nascimento da prisão. $1^{\text {a }}$ ed. Petrópolis, RJ: Editora Vozes, 1988.

FONSECA, V. Psicomotricidade. $2^{a}$ ed. São Paulo: Editora Martins Fontes, 1985.

FONSECA, V. Psicomotricidade. 4ª ed. São Paulo: Editora Martins Fontes, 1996.

FREIRE, J. B. Educação de corpo inteiro: teoria e prática da educação física. $1^{\mathrm{a}}$ ed. São Paulo: Editora Scipione: 1989.

GALVÃO, I. Henry Wallon: uma concepção dialética do desenvolvimento. $1^{\mathrm{a}}$ ed. Petrópolis, RJ: Editora Vozes, 1996. 
HURTADO, J. G. G. M. Dicionário de Psicomotricidade. $1^{a}$ ed. Porto Alegre, RS: Editora Prodil, 1991.

LAGRANGE, G. Manual de psicomotricidade. $1^{\text {a }}$ ed. São Paulo: Editora Lisboa, 1977.

LAPIERRE, A.; ACOUTURIER, B. A simbologia do movimento. $1^{\text {a }}$ ed. Porto Alegre, RS: Editora Artes Médicas, 1988.

LE BOULCH, J. A educação pelo movimento. $1^{\text {a }}$ ed. Porto Alegre, RS: Editora Artes Médicas, 1983.

LEDOUX, Michel H. Introdução à obra de Françoise Dolto. $1^{a}$ ed. Rio de Janeiro: Editora Zahar, 1991.

MARX, K.; ENGELS, F. A ideologia alemã. 6ª ed. São Paulo: Editora Hucitec, 1987.

MARX, K. O capital: crítica da economia política. 18a ed. Rio de Janeiro: Editora Civilização Brasileira, 2001.

MOLINARI, A. M. P.; SENS, S. M. A educação física e sua relação com a psicomotricidade. Revista Psicologia Educação Cultura, v. 3, n. 1, p. 85-93, 2003.

OLIVEIRA, G. C. Psicomotricidade, educação e reeducação num enfoque psicopedagógico. $3^{\text {a }}$ ed. Petrópolis, RJ: Editora Vozes, 1997.

PULASK, M. A. S. Compreendendo Piaget. $1^{a}$ ed. Rio de Janeiro: Editora Zahar, 1983.

SILVA, D. V. A psicomotricidade como prática social: uma análise de sua inserção como elemento pedagógico nas creches oficiais de Curitiba. Dissertação (Mestrado em Educação), Universidade Tuiuti do Paraná, Curitiba, PR, 2002.

VAYER, P.; TOULOUSE, P. Linguagem corporal. $1^{\text {a }}$ ed. Porto Alegre, RS: Editora Artes Médicas, 1982.

WALLON, H. As origens do caráter na criança. $2^{a}$ ed. São Paulo: Editora Nova Alexandria, 1995.

\section{Como citar este artigo:}

SILVA, Giuliano Roberto da, et al. A importância do desenvolvimento psicomotor na educação escolar, junto à educação física: uma revisão literária. Revista IberoAmericana de Estudos em Educação, Araraquara, v.12, n.1, p. 313-331, 2017. Disponível em: 〈http://dx.doi.org/10.21723/riaee.v12.n1.8278>. E-ISSN: 1982-5587.

Data de submissão: dez/2015

Aprovação final: jan/17 